\title{
МЕТОДОЛОГИЧЕСКИЕ ОСНОВЫ УЧЕТА ЭКСПОРТНЫХ ОПЕРАЦИЙ В СТРАНЫ ЕВРАЗИЙСКОГО ЭКОНОМИЧЕСКОГО СОЮЗА
}

\author{
Ю. В. Смирнова \\ (Московский гуманитарный университет)
}

Аннотация: В статье рассматривается вопрос о порядке проведения аттестации государственных гражданских служащих РФ, раскрывается порядок формирования и работы аттестационных комиссии. Также в статье указываются решения, принимаемые по результатам аттестации.

Ключевые слова: Таможенный Союз;таможенная территория; НДС; ЕАЭС; экспортная сделка; нормы валютного регулирования

\section{METHODOLOGICAL FOUNDATIONS OF ACCOUNTING FOR EXPORT TRANSACTIONSBETWEEN THE MEMBER STATES OF THE EURASIAN ECONOMIC UNION (EEU)}

\author{
Yu. V. Smirnova \\ (Moscow University for the Humanities)
}

\begin{abstract}
The article deals with theoretical and methodological foundations of accounting for export transactions between the member states of the Eurasian Economic Union (EEU). The entry into force of the Treaty on the EEU has led to progressive changes in foreign trade relations between the Russian Federation and former CIS states. Facts of economic life associated with the export of goods to the countries of the former CIS must find an accurate and full reflection in accounting.

Keywords: Customs Union; customs territory; VAT; Eurasian Economic Union; export transaction; rules of currency regulation

С 1 января 2015 г. вступил в силу Договор от 29 мая 2014 г. о Евразийском экономическом союзе(ЕАЭС). Эта международная организация региональной экономической интеграции, в которой, согласно нормативноправовому законодательству союза, обеспечивается свобода движения товаров, а также услуг, капитала и рабочей силы, и проведение скоординированной, согласованной или единой политики в отраслях экономики. На сегодня в нее входят: Республика Армения, Республика Беларусь, Республика Казахстан, Киргизская Республика и Российская Федерация.

Используемые понятия следует понимать следующим образом:
\end{abstract}


- государства - члены таможенного союза - государства-члены в значении, определенном «Договором о Евразийском экономическом союзе» от 29 мая 2014 г;

- единая таможенная территория таможенного союза (таможенная территория таможенного союза) - таможенная территория Союза;

- единая Товарная номенклатура внешнеэкономической деятельности таможенного союза (Товарная номенклатура внешнеэкономической деятельности) - единая Товарная номенклатура внешнеэкономической деятельности Евразийского экономического союза;

- единый таможенный тариф таможенного союза - единый таможенный тариф Евразийского экономического союза;

- Комиссия таможенного союза - Евразийская экономическая комиссия;

- международные договоры государств - членов таможенного союза - международные договоры в рамках Союза, в том числе международные договоры государств-членов, входящие в право Союза;

- таможенная граница таможенного союза (таможенная граница) таможенная граница Евразийского экономического союза;

- товар таможенного союза - товар Евразийского экономического союза(Договор о Евразийском ..., Электр. ресурс).Внешнеэкономическая деятельность (ВЭД) является неотъемлемой частью любой страны. Организации, желающие раздвинуть рамки своей хозяйственной деятельности за территорию Российской Федерации, сталкиваются с такими вопросами, как правила экспорта / импорта товаров и услуг, порядок ведения валютных операций при экспорте/импорте товаров и услуг, порядок налогообложения внешнеэкономической деятельности.

Чтобы правильно ориентироваться в ситуациях, связанных с реализацией товаров в страны - участницы ЕАЭС, необходимо знать ответы на эти и другие актуальные вопросы внешнеторговой деятельности.

Актуальными вопросами для бухгалтера, занимающегося учетом экспортных операций в странах Евразийского экономического союза, являются: навыки объективного отражения в бухгалтерском учете операций, связанных с экспортной деятельностью, правильное отражение экспортных операций в налоговом учете и налоговой отчетности в рамках операций, осуществляемых на территории единого экономического пространства. Также, необходимо учитывать нормы валютного регулирования операций, связанных с внешнеэкономической деятельностью, которые регламентируются валютным законодательством Российской Федерации.

При принятии организацией решения об экспорте продукции, работ, услуг предполагается получение в дальнейшем прибыли, например, от реализации товаров. В этой связи актуальным является вопрос объ- 
ективного отражения экспортной сделки по всем этапам ее проведения, что позволит организации избежать сложностей на пути формирования дохода от операции. Создание форм экономической интеграции и интеграция России в мировую экономику, развитие рыночных отношений, потребность привлечения иностранных инвестиций в экономику страны вывели на первый план вопросы создания и совершенствования эффективных методов учета и отчетности, соответствующих международным стандартам.

\section{Общие принципы и методология учета экспортных операций в ЕАЭС}

Для осуществления внешнеторговых сделок организация, занимающаяся внешнеторговой деятельностью, должна выполнять условия налогового, таможенного и валютного законодательства РФ. Участник внешнеэкономической деятельности должен четко представлять, что исполнение внешнеторговых сделок, как импортных, так и экспортных,требует особого внимания в зависимости от условий сделки (сроков исполнения сделки, специфики товара, условий оплаты и др.).

Осуществление экспортной деятельности субъекта внешнеэкономической деятельности начинается с заключения внешнеторгового контракта.

Важно отметить, что экспортер до момента подписания контракта и начала его исполнения должен позаботиться о вопросах получения лицензий на вывоз того или иного товара. Нормативными актами РФ определен перечень товаров, на экспорт или импорт которых предоставляется исключительное право. Сделки, осуществленные по экспорту или импорту товаров без лицензии, признаются ничтожными.

Лицензирующие органы выдают участникам внешнеторговой деятельности следующие виды лицензий:

• разовая лицензия - документ, выдаваемый заявителю на основании договора (контракта), оформившего внешнеторговую сделку, предметом которой является экспорт или импорт отдельного вида товара в определенном количестве. Срок действия разовой лицензии не может превышать 1 год со дня ее выдачи. В случае если в отношении товара введены временные количественные ограничения, срок действия такой лицензии заканчивается 1 января следующего года;

- генеральная лицензия - выдаваемый заявителю на основании решения Правительства Российской Федерации документ, разрешающий экспорт и (или) импорт отдельного вида товара в определенном количестве. Срок действия генеральной лицензии не может превышать 1 год со дня ее выдачи. В случае если в отношении товара введены временные 
количественные ограничения, срок действия такой лицензии заканчивается 1 января следующего года;

• исключительная лицензия - документ, предоставляющий заявителю исключительное право на экспорт и (или) импорт отдельного вида товара (Об утверждении Положений ..., 2005).

Подписание внешнеторгового контракта, защищающего интересы, как экспортера, так и его клиента, является важнейшим этапом деятельности участников ВЭД. Главной целью для экспортера является исполнение контракта, по которому он несет ответственность перед контрагентом и перед законодательством РФ.

Первым шагом после подписания контракта является оформление паспорта сделки в уполномоченном банке.

Паспорт сделки (ПС) - документ валютного контроля, содержащий сведения, необходимые в целях обеспечения учета и отчетности и осуществления валютного контроля по валютным операциям между резидентами и нерезидентами.

При осуществлении внешнеторговой деятельности в паспорте сделки указываются:

• номер и дата оформления паспорта сделки;

- сведения о резиденте и его иностранном контрагенте;

- общие сведения о внешнеторговой сделке (дата договора, номер договора (если имеется), общая сумма сделки (если имеется) и валюта цены сделки, дата завершения исполнения обязательств по сделке);

- сведения об уполномоченном банке, в котором оформляется паспорт сделки и через счета которого осуществляются расчеты по сделке;

- сведения о переоформлении и об основаниях для закрытия паспорта сделки (О валютном регулировании ..., 2003).

Паспорт сделки оформляется участником ВЭД в 2-х экземплярах. На каждый контракт оформляется один ПС в одном Уполномоченном банке.

В случае подписания контракта только на иностранном языке в Уполномоченный банк представляются оригинал и заверенная копия перевода на русский язык. После сравнения данных, указанных в ПС, и оригинала контракта последний (оригинал) возвращается участнику ВЭД. В случае заключения контракта, общая сумма по которому не превышает 50 тыс. долл. США по курсу иностранных валют к рублю, установленному ЦБ РФ на дату заключения контракта, паспорт сделки не оформляется.

Оформленный должным образом участником ВЭД паспорт сделки (копия) вместе с заверенной копией контракта передается в таможенные органы для оформления грузовой таможенной декларации при экспорте.

При зачислении на транзитный валютный счет денежных средств в иностранной валюте или валюте РФ на рублевый счет по контракту, по кото- 
рому открыт паспорт сделки, необходимо предоставить в банк 1 экземпляр справки о валютных операциях (СВО). Одновременно с СВО в банк предоставляются документы, связанные с проведением валютной операции.

Также, по документам, подтверждающим исполнение обязательств по контракту, в банк предоставляется справка о подтверждающих документах (СПД). Она предоставляется в одном экземпляре. Одновременно с СПД представляются документы, подтверждающие исполнение обязательств по контракту. При экспорте товаров в страны ЕАЭС:

-транспортные (перевозочные, товаросопроводительные) документы (TTH, CMR);

• коммерческие документы (счет-фактура);

- статистическая форма учета перемещения товаров, утвержденная постановлением Правительства РФ № 40 от 29.01.2011 г.

Статистическая форма представляется в банк после ее оформления и представления в таможенные органы. Ее не обязательно представлять одновременно с СПД.

СПД предоставляется в банк не позднее 15 рабочих дней после окончания месяца, в котором были оформлены подтверждающие документы.

Оформление таможенных документов на вывоз товаров осуществляется участником ВЭД (резидентом) самостоятельно или может быть передано по договору (за вознаграждение) таможенному представителю, что позволяет сократить затраты и время на оформление. В законодательном порядке таможенное оформление не будет производиться до того, как будут уплачены таможенные пошлины, акцизы, налоги

Исключение составляют правила Таможенного кодекса Таможенного союза (ТК ТС), т.к. с вступлением в силу 01.07.2010 г. ТК ТС изменились и многие требования к участникам ВЭД при осуществлении экспортноимпортных операций между организациями этих стран.

С 1 июля 2011 г. таможенный контроль на внутренних границах между странами - членами Таможенного союза отменен и перенесен на внешний контур. Между таможенными органами отправления и назначения, находящимися на территории Таможенного союза, обеспечен обмен электронными сообщениями о поступлении товара к месту назначения.

Согласно ТК ТС экспорт - процедура, в соответствии с которой товары Таможенного союза вывозятся с таможенной территории. Таким образом, перемещение товаров из России в страны ЕАЭС рассматривается как взаимная торговля.

В рамках взаимной торговли не взимаются таможенные платежи, применяется нулевая ставка НДС и/или освобождение от уплаты акцизов, а также не применяются меры нетарифного регулирования.

При экспорте товаров в страны-участницы ЕАЭС, товар не подлежит 
таможенному контролю. Он перемещается по территории ЕАЭС совершенно свободно.

Экспортные поставки товаров в страны ЕАЭС оформляются следующим комплектом документов:

- CMR - международная товарно-транспортная накладная, используемая для перевозок товаров автомобильным транспортом. Является обязательным документом для оформления экспортной поставки;

- Товарная накладная, или другой документ, подтверждающий реализацию товара;

- Счет-фактура с «нулевой» ставкой НДС;

-Документы, подтверждающие происхождение и безопасность вывозимого товара.

В зависимости от базисных условий поставки, предусмотренных контрактом, в обязанности грузоотправителя могут входить оплата транспортно-экспедиторских услуг по перевозке товара к месту назначения на основании договора и оформление транспортного документа.

Выручка от реализации товаров признается в размере договорной стоимости, пересчитанной в рубли по курсу иностранной валюты, установленному Банком России на дату реализации товаров (на дату перехода права собственности на товары к иностранному покупателю) (Положение по бухгалтерскому учету «Доходы организации» (ПБУ 9/99), утверждено Приказом Минфина России № 32н, 06.05.1999).

Выручка от реализации товаров в последующем не пересчитывается в связи с изменением курса иностранной валюты. Пересчету подлежит дебиторская задолженность покупателя по оплате реализованных товаров. Задолженность пересчитывается на отчетные даты и на дату ее погашения. В результате пересчета дебиторской задолженности покупателя в бухгалтерском учете могут возникать положительные (отрицательные) курсовые разницы. Такие разницы учитываются на счете 91 «рочие доходы и расходы» (субсчет 91-1 «Прочие доходы» или субсчет 91-2 «Прочие расходы») (Положение по бухгалтерскому учету ..., 2007).

Если право собственности в момент отгрузки товаров на экспорт покупателю не передается, то товар учитывается по дебету счета 45 «Товары отгруженные» и кредиту счета 41 «Товары»/43 «Готовая продукция».

Если же, в этот момент право собственности передается, то в учете отражается реализация товара по дебету счета 62 «Расчеты с покупателями и заказчиками» и кредиту счета 90 «Продажи», субсчет 1 «Выручка».

Фактическая себестоимость реализованного товара включается в себестоимость продаж следующей записью:

Дебет 90 «Продажи» субсчет 2 «Себестоимость продаж», Кредит 45 «Товары отгруженные» (41 «Товары», 43 «Готовая продукция»). Запись по 
счету 45 «Товары отгруженные» не производится, если право собственности на товар переходит к покупателю в момент отгрузки.

Если организация при приобретении товара уже приняла к вычету НДС, то при его отгрузке на экспорт в учете следует сделать проводку по восстановлению налога:

Дебет 19 «Налог на добавленную стоимость по приобретенным ценностям», Кредит 68 «Расчеты по налогам и сборам», субсчет «НДС».

На последнее число квартала, в котором собран полный пакет документов, подтверждающих ставку НДС в размере 0\%, в учете делается запись: Кредит 19 «Налог на добавленную стоимость по приобретенным ценностям». Данная проводка отражает принятие НДС к вычету.

Если договор на поставку будет заключен в иностранной валюте, на отчетную дату и (или) на дату получения оплаты от покупателя будет отражаться сумма положительной или отрицательной курсовой разницы по расчетам с покупателем:

Положительная курсовая разница отражается по дебету счета 62 «Расчеты с покупателями и заказчиками» и кредиту счета 91 «Прочие доходы и расходы» Субсчет 1 «Прочие доходы»;

Отрицательная курсовая разница учитывается по дебету счета 91 «Прочите доходы и расходы» Субсчет 2 «Прочие расходы» и кредиту счета 62 «Расчеты с покупателями и заказчиками».

Сумма полученных денежных средств от покупателя отражается следующей записью: Дебет 51 «Расчетные счета», Кредит 62 «Расчеты с покупателями и заказчиками» для операций в рублях Российской Федерации; Дебет 52 «Валютные счета», Кредит 62 «Расчеты с покупателями и заказчиками» для операций в валюте.

При экспорте товаров применяется нулевая ставка НДС при условии документального подтверждения факта экспорта. Порядок уплаты НДС при экспорте товаров из России в страны ЕАЭС, устанавливается Договором о ЕАЭС, в том числе Приложением № 18 к Договору.

Для подтверждения нулевой ставки НДС организация-экспортер представляет в налоговый орган одновременно с налоговой декларацией следующие документы (их копии):

•Договор (контракт) с учетом изменений, дополнений и приложений к нему, на основании которого осуществляется экспорт товаров;

- Выписка банка, подтверждающая фактическое поступление выручки от реализации экспортированных товаров на счет налогоплательщикаэкспортера, если иное не предусмотрено законодательством государствачлена;

- Заявление о ввозе товаров и уплате косвенных налогов, составленное по форме, предусмотренной отдельным международным межведом- 
ственным договором, с отметкой налогового органа государства-члена, на территорию которого импортированы товары, об уплате косвенных налогов (освобождении или ином порядке исполнения налоговых обязательств) (далее - заявление) (на бумажном носителе в оригинале или в копии по усмотрению налоговых органов государств-членов) либо перечень заявлений (на бумажном носителе или в электронном виде с электронной (электронно-цифровой) подписью налогоплательщика);

-Транспортные (товаросопроводительные) и (или) иные документы, предусмотренные законодательством государства-члена, подтверждающие перемещение товаров с территории одного государства-члена на территорию другого государства-члена. Указанные документы не представляются, если для отдельных видов перемещения товаров, в том числе перемещения товаров без использования транспортных средств, оформление этихдокументов не предусмотрено законодательством государствачлена;

-Иные документы, подтверждающие обоснованность применения нулевой ставки НДС, предусмотренные законодательством РФ. Например, договоры комиссии (агентские договоры, договоры поручения), если товары с территории РФ в государства - члена ЕАЭС поставляются через посредников(Протокол о порядке взимания ..., 2014: Электр.ресурс).

Заявление содержит реквизиты, аналогичные реквизитам Грузовой таможенной декларации. Заявление состоит из трех разделов и Приложения: разделы 1 и 3 заполняет налогоплательщик, а второй - налоговый орган.

В разделе 1 указываются продавец и покупатель, наименование товара, а также его количество и стоимость. Кроме того, приводятся налоговые ставки, налоговая база, сумма налогов и т.д. Раздел имеет 20 основных количественных и качественных показателей (граф), обязательных для заполнения.

В разделе 2 должна стоять отметка о регистрации заявления при представлении в налоговый орган и отметка налогового органа об уплате косвенных налогов.

Раздел 3 содержит данные о продавце, комитенте, доверителе или принципале, а также о покупателе, комиссионере, поверенном или агенте.

Заявление должно представляться налогоплательщиком на бумажном носителе (в четырех экземплярах) и в электронном виде в налоговый орган по месту постановки на учет. Оно обязательно подписывается руководителем организации или ее представителем и главным бухгалтером или индивидуальным предпринимателем.

Заявление первоначально представляет импортер другого государства-члена ЕАЭС в налоговый орган на бумажном носителе (в четырех 
экземплярах) и в электронном виде. Два экземпляра с отметкой налогового органа этого государства он передает своему контрагенту-экспортеру, а тот включает их в число подтверждающих документов.

На бумажном заявлении должна стоять отметка о том, что покупатель товаров уплатил в стране-импортере косвенный налог. Такую отметку ставит налоговый орган того государства-члена ЕАЭС, где находится покупатель-импортер товаров.

В течение десяти рабочих дней со дня поступления Заявления и документов, предусмотренных Протоколом о порядке взимания косвенных налогов и механизме контроля за их уплатой при экспорте и импорте товаров, выполнении работ, оказании услуг, являющимся приложением № 18 к Договору о Евразийском экономическом союзе от 29 мая 2014 г., должностное лицо налогового органа, принявшего Заявление, должно его рассмотреть и подтвердить факт уплаты косвенных налогов (освобождения либо иного способа уплаты) либо мотивированно отказать в соответствующем подтверждении

Указанные выше документы представляются в налоговый орган в течение 180 календарных дней с даты отгрузки (передачи) товаров, которой признается дата первого по времени составления первичного бухгалтерского (учетного) документа, оформленного на покупателя товаров.

В случае, если полный пакет документов не собран в течение 180 календарных дней, то нулевая ставка НДС не применяется, а операции по реализации товаров подлежат обложению НДС по ставкам $10 \%$ или $18 \%$. Налоговая база, в таком случае, определяется на день отгрузки (передачи) товаров.

Организация-экспортер вправе принять к вычету НДС, предъявленный ей при приобретении товаров, экспортируемых в страны-участницы ЕАЭС.

Согласно п. 9 ст. 167 НК РФ налоговая база по операциям, по которым собран полный пакет документов за 180 дней, определяется на последний день налогового периода, в котором собраны подтверждающие документы. В тот же момент налогоплательщик получает право и на вычет «входного» налога по товарам, приобретенным для экспортной поставки (разумеется, при соблюдении общих условий для применения вычета).

Вычет НДС, предъявленного при приобретении товаров, реализованных на экспорт в страны ЕАЭС, производится на последнее число квартала, в котором собран полный пакет документов, подтверждающий ставку в размере 0\%(Налоговый кодекс Российской Федерации ..., 2000).

В декларации при этом подлежит заполнению разд. 4, а вместе с отчетностью в инспекцию должны быть представлены подтверждающие документы (там же). 
Согласно письмам Минфина РФ, налогоплательщик вправе отложить (до сдачи отчетности) представление в ИФНС документов, подтверждающих экспорт, если они собраны в пределах отведенного срока, но в том же квартале, на который приходится его окончание.

Если за рубеж экспортируются товары, по которым произведен вычет «входного» НДС, налог нужно восстановить. Основанием тому является особый порядок для вычета НДС, предусмотренный в отношении операций, облагаемых по нулевой налоговой ставке. Указанные вычеты налогоплательщик вправе заявить в момент определения налоговой базы, установленный ст. 167 НК РФ, в порядке, предусмотренном п. 3 ст. 172 НК РФ, то есть при подтверждении ставки $0 \%$.

Восстановление суммы НДС производится поставщиком в налоговом периоде, в котором осуществляется отгрузка товаров на экспорт. Данные суммы отражаются по строке 100 раздела 3 налоговой декларации. На момент определения налоговой базы, установленный п. 9 ст. 167 НК РФ, указанная сумма НДС принимается к вычету (там же).

Для отражения экспортных операций в декларации предусмотрено три раздела:

- раздел 4 - заполняется в том случае, когда предприятие укладывается в сроки сбора (не больше ста восьмидесяти дней) необходимого пакета документов;

- раздел 5 - заполняется, если обоснованность применения нулевой ставки подтверждена или не подтверждена документально;

- раздел 6, в который вносятся данные, если предприятие не успело собрать всю нужную документацию в установленные сроки. Тогда объем налога исчисляется по ставке десять или восемнадцать процентов и подается уточненная декларация, в которой заполнен данный раздел.

Товарный учет и формирование себестоимости товара осуществляется на счете 41 «Товары». При аналитическом учете используются следующие субсчета:

• 41.01 «Товары на складах»;

• 41.02 «Товары в розничной торговле»;

• 41.03 «Тара под товаром и порожняя»;

• 41.04 «Покупные изделия».

Сумма задолженности покупателей учитывается на счете 62 «Расчеты с покупателями и заказчиками» с применением следующих субсчетов:

• 62.01 «Расчеты с покупателями и заказчиками»;

• 62.02 «Расчеты по авансам полученные»;

• 62.21 «Расчеты с покупателями и заказчиками (в валюте)»;

- 62.22 «Расчеты по авансам полученным (в валюте);

•62.31 Расчеты с покупателями и заказчиками (в у.е.)»; 
- 62.32 «Расчеты по авансам полученным (в у.е.);

Учет выручки ведется на счете 90 «Продажи» в соответствии с установленным Учетной политикой организации планом счетов бухгалтерского учета. Организация не ведет раздельный учет выручки по товарам, облагаемым по налоговым ставкам $10 \%$ и $18 \%$.

Организация реализует товар как на внутреннем, так и на внешнем рынке. Для организации раздельного учета по НДС на счете 19 «НДС по приобретенным ценностям» аналитический учет ведется с использованием следующих субсчетов:

• 19.01 «НДС при приобретении ОС»;

• 19.02 «НДС по приобретенным НМА»;

• 19.03 «НДС по приобретенным МПЗ»;

• 19.04 «НДС по приобретенным услугам»;

• 19.05 «НДС, уплаченный при ввозе товаров на территорию РФ»;

• 19.06 «Акцизы по оплаченным материальным ценностям»;

• 19.07 «НДС по товарам, реализованным по ставке 0\%»;

- 19.08 «НДС при строительстве основных средств»;

• 19.09 «НДС по уменьшению стоимости реализации».

Расчеты с бюджетом по НДС ведутся на счете 68 «Расчеты по налогам и сборам» субсчет 02 «Налог на добавленную стоимость».

В отношении объектов учета, приобретенных для реализации товаров, операции по реализации которых облагаются по налоговой ставке 0\%, «входящий налог» на добавленную стоимость принимается к вычету на последнее число месяца, в котором собран полный пакет документов, предусмотренных ст.165 НК РФ. При этом, вся сумма «входного» НДС, предъявленная поставщиками в текущем налоговом периоде и отраженная по дебету счета 19 «НДС по приобретенным ценностям» на различных субсчетах принимается к возмещению при выполнении всех обязательных условий согласно ст.169, 171, 172 НК РФ (там же).

Если в налоговом периоде были отгрузки (реализация) товаров на экспорт, то сумма входного НДС, ранее принятый к возмещению, восстанавливается на дату отгрузки товаров на экспорт по методу партионного учета для целей НДС.

Если на момент импорта товаров известно, что товар (его часть) будет реализован на экспорт, сумма «входного» НДС не возмещается в пропорции, приходящейся на долю товара на экспорт, и учитывается по дебету счета 19 «НДС по приобретенным ценностям» до тех пор, пока организация не соберет необходимый пакет документов. После того, как будет собран полный пакет документов для подтверждения 0\% ставки НДС, остаток по счету 19.05 принимается к возмещению.

Руководствуясь нормами законодательства, диктующими различный 
порядок отражения хозяйственных операций по учету импортных товаров и товаров российского производства, НДС и других налогов, в организации разработан и закреплен различный порядок учета импортных операций и раздельного учета на различных участках учета.

Расчеты с таможенным органом организация ведет с использованием счета 60 «Расчеты с поставщиками и подрядчиками».

При формировании показателей бухгалтерского и налогового учета, а также во всех случаях использования в нормативно-правовых актах принципа существенности в организации устанавливается уровень существенности, который служит основным критерием признания фактов существенными. Существенными признаются обстоятельства, значительно влияющие на достоверность отчетности. Существенной признается сумма, отношение которой к общему итогу соответствующих данных за отчетный год составляет не менее $5 \%$.

\section{СПИСОК ЛИТЕРАТУРЫ}

Договор о Евразийском экономическом союзе от 29.05.2014 г. (ред. от 10.10.2014, с изм. от 08.05.2015) [Электронный ресурс]//Официальный сайт Евразийской экономической комиссии. URL: https://docs.eaeunion.org/ sites/storage0/Lists/Documents/a089f4c6-02da-4461-b033-3f5d122e0020/ e57db9f2-9589-4b26-be1e-b1a43862c6ed_635375701449140007.pdf (дата обращения: 05.06.2015);

Налоговый кодекс Российской Федерации. Часть вторая от 05.08.2000 № 117-ФЗ ред. от 06.04.2015) (2000) // Парламентская газета. 10.08. № 151152.

О валютном регулировании и валютном контроле: федеральный закон РФ от 10 декабря 2003г. № 173-ФЗ (ред. от 04.11.2014) (2003) // Парламентская газета. 17.12. № 233.

Об утверждении Положений о лицензировании в сфере внешней торговли товарами и о формировании и ведении федерального банка выданных лицензий: постановление Правительства РФ от 09.06.2005 № 364 (ред. от 05.08.2014) (2005) // Российская газета. 15.06.

Положения по бухгалтерскому учету «Учет активов и обязательств, стоимость которых выражена в иностранной валюте» (ПБУ 3/2006), утверждено Приказом Минфина РФ от 27.11.2006 № 154н (ред. от 24.12.2010) (2007) // Российская газета. 07.02. № 25.

Протокол о порядке взимания косвенных налогов и механизме контроля за их уплатой при экспорте и импорте товаров, выполнении работ, оказании услуг: Приложение № 18 к Договору о Евразийском экономическом союзе от 29.05.2014 [Электронный ресурс] // Официальный сайт Евразийской экономической комиссии. URL: https://docs.eaeunion.org/ 
sites/storage0/Lists/Documents/a089f4c6-02da-4461-b033-3f5d122e0020/ e57db9f2-9589-4b26-be1e-b1a43862c6ed_635375701449140007.pdf (дата обращения: 05.06.2015).

Смирнова Юлия Викторовна -доцент кафедры статистики, бухгалтерского учета и маркетинга Московского гуманитарного университета, аудитор, член саморегулируемой организации аудиторовнекоммерческого партнерства «Аудиторская Ассоциация Содружество», член Международной Федерации бухгалтеров (IFAC). Адрес: 111395, Россия, г. Москва, ул. Юности, д. 5. Тел.: +7 (499) 374-58-60. Эл.адрес: olgavmaria@yandex.ru

Smirnova Yuliya Viktorovna, Associate Professor, Department of statistics, accounting and marketing, Moscow University for the Humanities; auditor;Member, Self-regulatory organization of auditors Non-commercial partnership SODRUZHESTVOAUDITORASSOCIATION;Member,International Federation of Accountants. Postal address: 5 Yunosti St., 111395 Moscow, Russian Federation. Tel.: +7 (499) 374-58-60.E-mail: olgavmaria@yandex.ru 